Esta revista forma parte del acervo de la Biblioteca Jurídica Virtual del Instituto de Investigaciones Jurídicas de la UNAM

\title{
GRANDES PROBLEMAS. TRANSPARENCIA: PROMESAS Y DESAFÍOS
}

\section{Mireya SANTILLÁN CÁRDENAS*}

Proporcionar información a los ciudadanos sobre asuntos públicos, y sobre el quehacer y desempeño gubernamental, se ha convertido en una condición indispensable de las democracias contemporáneas. Incluso, la implementación de políticas de transparencia es considerada como un referente de la calidad de la democracia, debido a que al abrirse los procesos de toma de decisiones del gobierno, se someten al escrutinio público, lo que se convierte en una herramienta del ciudadano para ejercer control e influencia en dichos procesos, factor indispensable en los regímenes democráticos consolidados.

En los últimos años, los estudios sobre transparencia desde diversos enfoques y campos de estudio se han multiplicado, sobre todo a partir de iniciado el siglo XXI, como consecuencia de la creación e implementación de leyes y políticas de transparencia en varios países. En México, el interés particular de académicos, investigadores y organizaciones de la sociedad civil por profundizar en esta área de estudio, sin menoscabo de los estudios previos, ha crecido con la construcción y delimitación del marco jurídico de la transparencia, que inició en 2002 con la promulgación de la Ley Federal de Transparencia y Acceso a la Información Pública Gubernamental (LFTAIPG), y que ha tenido una etapa de reciente cambio en 2015 al modificarse la Ley General de Transparencia y Acceso a la Información Pública (LGTAIP).

Egresada de la Licenciatura en Ciencias Políticas y Administración Pública de la Facultad de Ciencias Políticas de la UNAM. Profesora ayudante en la misma institución, y asistente de investigación en el Instituto de Investigaciones Jurídicas de la UNAM, mireya. santillan@gmail.com. 
Esta revista forma parte del acervo de la Biblioteca Jurídica Virtual del Instituto de Investigaciones Jurídicas de la UNAM

En este contexto, Jacqueline Peschard, ${ }^{* *}$ en su libro Transparencia: promesas y desafíos, que forma parte de la colección Grandes Problemas, coeditado por El Colegio de México y la UNAM en 2017, realiza una importante aportación al compilar, en una obra, las cuestiones más relevantes sobre la transparencia que han estado dispersas en diversos estudios: ¿qué es la transparencia?, ¿qué ha pasado con el desarrollo de la transparencia en las democracias contemporáneas?, ¿qué ha pasado con el desarrollo de la transparencia en México?, ¿cuál ha sido el desarrollo normativo e institucional de la transparencia en México y América Latina?,¿cuál ha sido la gestión de archivos en torno al acceso a la información?, ¿cuál es el estado - de la relación entre transparencia y la rendición de cuentas?, ¿cuál es el - estado de la relación entre la transparencia y la corrupción?

Peschard realiza una amplia revisión de la literatura, no sólo especializada en el tema, sino también asociada a las materias de ciencia política y sociología. En su libro, desarrolla un preciso estado del arte de la transparencia, en donde se pueden identificar ideas de teóricos y filósofos políticos, así como datos — de estadísticas, indicadores, bases de datos, entre otros- y referencias — provenientes principalmente de literatura especializada - que sustentan su análisis y reflejan su extenuante investigación.

Con una redacción fluida, clara y analítica, la autora, en cinco capítulos, explica con facilidad el balance histórico y actual de los avances en la creación e implementación de medidas de transparencia en el contexto nacional e internacional, así como sus problemas y retos. En el desarrollo de la obra, se establecen vínculos entre transparencia y democracia, transparencia y rendición de cuentas, transparencia y participación, y transparencia y corrupción.

En el primer capítulo, titulado "Los dilemas del poder: entre el secreto y la publicidad”, mediante un recorrido histórico, se establece una aproximación conceptual y teórica sobre la transparencia, después de precisar las relaciones entre el poder y el secreto, y el poder y la publicidad; el primero como herramienta indisociable del poder para mantener la obediencia

** Es doctora en ciencias sociales por el Colegio de Michoacán, profesora titular en la Facultad de Ciencias Políticas de la UNAM desde 1979, y coordinadora del Seminario Universitario de Transparencia. Ha ocupado distintos cargos en organismos autónomos, recientemente como integrante del Comité de Participación Ciudadana del Sistema Nacional Anticorrupción (SNA). Sus principales líneas de investigación son: democracia, sistemas políticos, partidos y procesos electorales, cultura política, transparencia, derecho de acceso a la información, rendición de cuentas, y corrupción. De ellas se han desprendido diversas obras de su autoría, tal como su libro previo a la obra citada, titulado Hacia el Sistema Nacional de Transparencia de 2016. 
Esta revista forma parte del acervo de la Biblioteca Jurídica Virtual del Instituto de Investigaciones Jurídicas de la UNAM

de los gobernados, y el segundo como característica esencial del modelo democrático, y consecuencia del establecimiento de derechos fundamentales y libertades.

El segundo capítulo, "Dimensiones de la noción contemporánea de transparencia”, aborda tres ejes principales: se definen las condiciones necesarias para satisfacer los requisitos mínimos de la transparencia y el derecho de acceso a la información; se establecen los límites y excepciones a la transparencia, y se estudia la transparencia y el derecho de acceso a la información en otros poderes y órganos del poder público, más allá del Poder Ejecutivo.

En el tercer capítulo, "Diseños institucionales para la transparencia y el acceso a la información”, se aborda el diseño y construcción institucional de la transparencia con referentes históricos internacionales; asimismo, se analizan modelos que se han elaborado para asegurar el cumplimiento de los principios de transparencia, así como el impulso de la transparencia en América Latina, dado su contexto histórico-político.

En el cuarto capítulo, "El largo camino hacia la transparencia en México”, Peschard ofrece una mirada histórica sobre el avance en las prácticas de transparencia a la par del desarrollo del proceso de transición a la democracia en nuestro país. En este apartado, la autora enfatiza la importancia del activismo de la sociedad civil organizada para impulsar la primera ley de transparencia; la creación del órgano garante autónomo que impulsa el derecho de acceso a la información y la transparencia, y el aumento en las exigencias de transparencia como parte del contexto internacional.

Finalmente, en el quinto y último capítulo, "Más allá de la transparencia”, se abordan los obstáculos y retos para la transparencia, y se establece un vínculo entre las relaciones de la transparencia con la rendición de cuentas y la corrupción, en donde se argumenta que la transparencia debe orientarse hacia la rendición de cuentas, y ambas deben tener como meta la prevención y erradicación de la corrupción.

Como parte de las conclusiones y reflexiones finales, siguiendo a la autora, la transparencia es un medio indispensable para construir una sociedad democrática, pues se debe tener información para ejercer mejor los derechos, vigilar lo que hace la autoridad, e incidir en los asuntos públicos. La transparencia debe verse como una herramienta y como una categoría relacional, es decir, no se puede ver simplemente como una serie de acciones de las autoridades o sujetos obligados sobre lo que hacen y deciden, sino que lo importante es dar a conocer esa información para que los ciudadanos se apoderen de ella, y así puedan tener una mayor influencia en 
Esta revista forma parte del acervo de la Biblioteca Jurídica Virtual del Instituto de Investigaciones Jurídicas de la UNAM

la toma de decisiones, por lo que, aunque sea insuficiente, no puede ser sustituida. En este orden de ideas, los ciudadanos deben hacer uso de la transparencia para mejorar la gestión pública y hacerla más responsable para que dé respuesta a sus demandas. De esta manera, resulta indispensable modificar las relaciones entre gobierno y sociedad para hacerlas más cercanas, y así se pueda generar un diálogo de intercambio entre gobernados y gobernantes sobre el acontecer público para hacer que la transparencia se convierta en una adecuada rendición de cuentas.

En suma, en Transparencia: promesas y desafíos se pasa revista a todo lo que se debe saber sobre la historia y la experiencia de la transparencia en - México y en otros países. De esta forma, el lector interesado en el tema en-

- contrará no sólo las primeras nociones sobre transparencia y el tránsito hacia la implementación de políticas concretas en esta materia, sino también una invitación a reflexionar sobre los retos pendientes y las aspiraciones para fomentar una verdadera rendición de cuentas que sirva como contención a los problemas de corrupción.

\section{Bibliografía del Libro RESEÑAdo}

Peschard, Jacqueline, 2017, Grandes problemas. Transparencia: problemas y desafíos, México, El Colegio de México-UNAM, 300 pp. 